\title{
Anti-tubercular substances produced by plants
}

\author{
Żaneta Polak', Lucyna Kapka-Skrzypczak ${ }^{1,2}$ \\ 1 Institut of Rural Health in Lublin, Poland \\ ${ }^{2}$ Department of Medical Biology and Translational Research, Faculty of Medicine, University of Information Technology \\ and Management, Rzeszów, Poland
}

Polak Ż, Kapka-Skrzypczak L. Anti-tubercular substances produced by plants. J Pre-Clin Clin Res. 2017; 11(2): 147-152. doi: 10.26444/jpccr/81231

\begin{abstract}
Tuberculosis is one of the common causes of death worldwide, and according to the World Health Organization, in 2015, about $10.4 \mathrm{mln}$ people globally is suffering from that disease. Despite great development in medicine and discovery of many antimycobacterial drugs, tuberculosis remains an unsolved problem. The populations of countries in Africa, Asia and South America have difficult access to hygiene, medical care and medicines, and they therefore resort to consulting traditional practitioners who mainly use drugs from natural sources which they prepare themselves. Plants are the biggest source of such medicines and are used as extracts, decoctions or powders, often without any evidence of their actual activity. Isolates from plants sometimes contain unknown substances or some second metabolites of microorganisms. In vitro studies have shown that some of these medicines have effective antimycobacterial properties, even against clinical, resistant strains. This is hopeful in the situation where more and more cases of tuberculosis prove to be resistant to standard drugs. Extracts of medicinal plants are often synergistic with synthetic drugs. Substances with insufficient MIC can be a basis for derivatives which have better properties. This thesis summarizes the current international knowledge of the use of plant substances used in the treatment of tuberculosis that could be potential new antituberculous drugs.
\end{abstract}

\section{Key words}

tuberculosis, endophytes, plant medicines, natural drugs, natural compounds

\section{INTRODUCTION}

The 'white plague' is the original name of tuberculosis, also known as consumption, and is a disease known since the times of Hippocrates.

Tuberculosis is caused by Mycobacterium tuberculosis discovered by Robert Koch in 1882. Generally, tubercular changes are located in the lungs, but can also occur in other tissues, e.g. bones or brain. Humans can be infected by inhalation during breathing. Although infection is very easy, tuberculosis is not highly infective. Reduced immunity and malnutrition favour infection [1].

Tuberculosis is one of the common causes of death worldwide, and according to the World Health Organization, in 2015 , about $10.4 \mathrm{mln}$ people globally contracted the disease. The most endangered populations are in Africa and Southeast Asia - 275 and 246 cases per 100,000 people, respectively. In these areas hygiene and access to medicines are at a low level and the density of the population constantly increases, which is one of many factors conducive to the morbidity due to tuberculosis. In contrast, morbidity in both Americas was 27 cases per 100,000 population, whereas in Europe this ratio was 36 cases per 100,000 inhabitants. The CFR (case fatality ratio) varies between $5 \%$ in countries such as Sweden, Norway and China, and more than $20 \%$ in some parts of South Africa. Tuberculosis concomitant with HIV is even more dangerous; for comparison, the CFR was more than 50\% in patients with tuberculosis and HIV in South Africa. Year by year, morbidity due to tuberculosis decreases; however, it is still creates a threat, especially in countries of the Third World [2].

The first effective anti-tuberculous drug was streptomycin, introduced after the Second World War and has therefore

Adress for correspondence: Żaneta Polak, Institut of Rural Health in Lublin, Jaczewskiego 2, 20-090 Lublin, Poland

E-mail: polak.zaneta@imw.lublin.pl

Received: 6 December; accepted: 15 December 2017

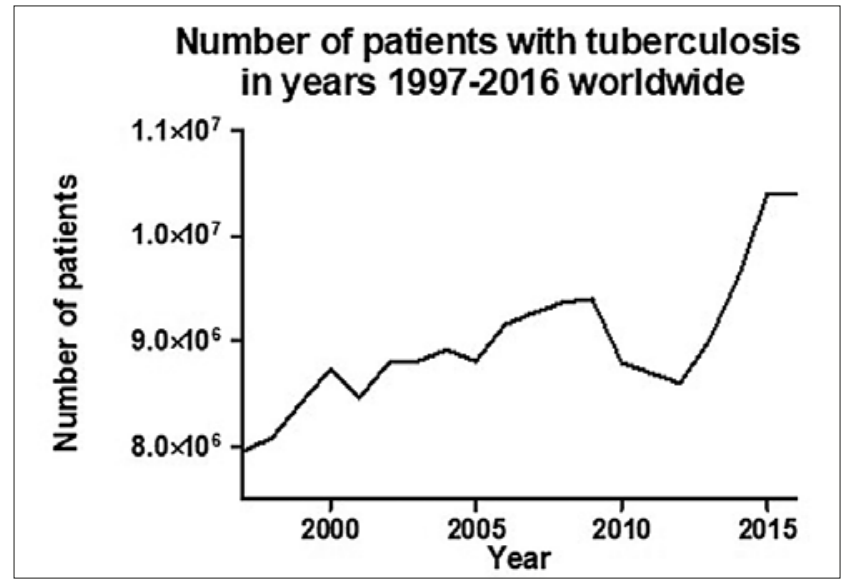

Figure 1. Number of patients with tuberculosis 1997-2016 worldwide [2]

been available for about 70 years, at a time when it was a breakthrough discovery and spectacular development. Although since then many new anti-tuberculous drugs have been discovered, treatment of the disease is still not an easy task. Strategies to control this disease are based on prevention and treatment; however, they are insufficient. An increasing number of new resistant strains continue to appear, especially in hospitals. Patients with MDR-TB (multi-drug resistance) or XDR-TB (extensively drug resistance tuberculosis) become a normal but still unresolved situation. To justify alarming reports by the WHO, in 1997-2004 in Poland, only one strain XDR was found, but in 2008 this increased to 13 [3, 4].

Increasing resistance limits the pharmacological capabilities and use of available medications which, in addition to the desire to shorten therapy, limit drug interactions and improve drug safety profile, is the main reason for finding new substances that have anti-tubercular effects. The synthesis and study of new drugs is a long-term process, which is why scientists have returned to the natural 
sources of medicines. Researchers have studied many plants to find those which have anti-tubercular properties. In this review, the authors present recent knowledge about natural drugs from plants.

Traditional use. Plants are well known in traditional folk medicine, and from the most ancient times people have treated themselves with natural medicines in various forms. The first step was to use the whole plant or its parts, the leaves or flowers; next, people prepared decoctions and infusions. Extracts, which are the most popular today, were prepared by better educated people who knew folk medicine. Most of the natural medicines were used without any proof of their effectiveness against tuberculosis.

In recent times, researchers have investigated the natural medicines used in the treatment of tuberculosis in Uganda, and discovered that traditional medical practitioners treat with 88 various plants, 15 of which have not been identified. Some were used more often than others, for example, the leaves of Eucalyptus spp., Ocimum suave and Momordica foetida and the root bark of Warburgia salutaris. It is an interesting fact that traditional medicinal practitioners sometimes add honey, Zingiber officinale or rock salt. Generally, they make decoctions from these parts of plants and the dosage is 1-2 teaspoons or tablespoons [5]. A similar situation exists in Laos, where healers use 77 various plants, of which only $10 \%$ display any anti-mycobacterial activity. The most potent seems to be Marsypopetalum modestum MIC from 1.33-23.52 $\mu \mathrm{g} / \mathrm{ml}$ [6]. A review of folk medicine plants from Southeast Asia shows that $24.2 \%$ of extract from 132 species used in ethnomedicine have significant anti-mycobacterial activity (MIC less than $100 \mu \mathrm{g} / \mathrm{ml}$ ). Researchers isolated pure compounds and found that the most active of them was 1'-acetoxychavicol acetate, isolated from Alpina galangal with an MIC value of $0.024 \mu \mathrm{g} / \mathrm{ml}$ [7]. In Mexico, healers use 187 plants to treat respiratory diseases that may be associated with tuberculosis, 63 of which have been assayed for anti-mycobacterial activity [8]. Traditional medicine is simply one approach to treatment and seems to be ineffective, in fact, people from undeveloped areas, without access to medicines and physicians, have to rely on traditional medicinal practitioners. The healer is the first contact person for the local population, without whom people in the Third World countries would die from ordinary infections. Many researches show that crude extracts of medicinal plants or isolated compounds could be used as complementary treatment or an alternative to synthetic drugs. Many of

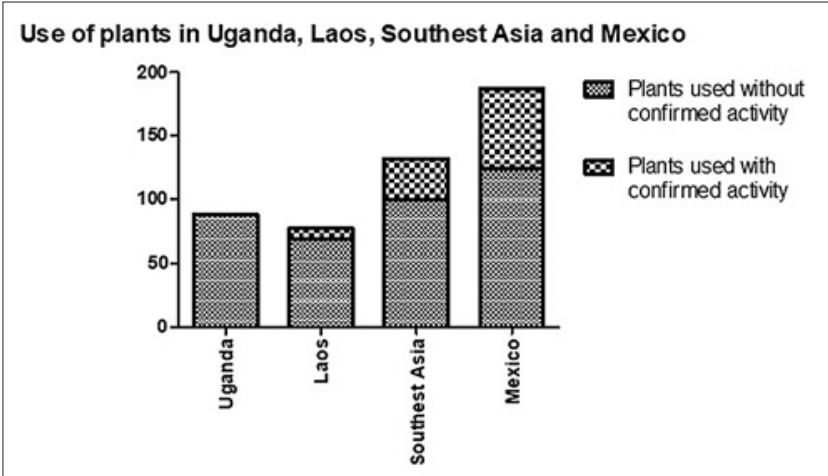

Figure 2. Ratio of plants used which have confirmed antimycobacterial properties in Uganda, Laos, Southeast Asia and Mexico [5-8] these plants show some activity against microbes or in nonbacterial disorders. There are many plants traditionally used in tuberculosis treatment.

Extracts and natural substances isolated from plants. Asia is a region where traditional medicines are still used and people use untested plants with non-confirmed properties, many of which prove to have anti-mycobacterial activity. One such plant is Premma odorata, commonly known in the Philippines. Researchers tested the extract, pure compounds and mixtures of these compounds. Pure substances displayed greater anti-mycobacterial potential than mixtures, which means that it is justified to use pure substances and not the whole plant or extract [9]. Another plant used in folk medicine to treat bronchitis in the Philippines is Pandanus tectorius, an evergreen tree which contains tirucallanetriterpene as the most active compound (MIC $64 \mu \mathrm{g} / \mathrm{ml}$ ) [10]. Uvaria rufa is one more plant from the Philippines which has been investigated against $M$. tuberculosis. Fractions indicated various anti-mycobacterial activities - from 8 , for lead acetate-treated chloroform extracts, to more than $128 \mu \mathrm{g} / \mathrm{ml}$. Further research revealed that the flavonoids from that plant are responsible for anti-mycobacterial activity [11]. A medium-sized deciduous tree named Ehretia longiflora is well known in China, Indochina and the forests of Taiwan. Two of the many isolates from root tissue are active against M.tuberculosis $\mathrm{H} 37 \mathrm{Rv}$, both are derivates of quinonoids and have MIC values of 25.0 and $26.2 \mu \mathrm{g} / \mathrm{ml}$ [12]. Very promising results have been obtained in tests of Caesalpinia sappan, a shrub from Southeast Asia and the Malaysian Archipelago. The main active substance isolated from the heartwood of that plant is 3-deoxysappanchalcone, which displays activity not only against $M$. tuberculosis, but also against multidrugresistance and extensively drug-resistance tuberculosis strains. The MIC is within the range $3.125-12.5 \mu \mathrm{g} / \mathrm{ml}$, which is much higher than rifampicin in most cases [13]. Diterpenoids, as the researchers have discovered, possess some anti-mycobacterial properties. Croton tonkinensis, a shrub from Vietnam, is especially rich in these types of substances. Characteristic for this plant are compounds containing kaurane and its derivatives. The best activity against $\mathrm{H} 37 \mathrm{Ra}$ is an MIC value less than $1.56 \mu \mathrm{g} / \mathrm{ml}$, and against resistance strains, $1.56 \mu \mathrm{g} / \mathrm{ml}$ and higher. It is not very often that the MIC against reference and resistance strains are the same [14]. Exotic orchids are known as household ornamental plants. In the Arunachal Pradesh district of northeastern India, there are 550 species of orchids used by inhabitants as medicinal plants, some of which display good antimycobacterial activity in in vitro assays. The root of Rhynchostylis retusa grows in the Himalayas and is used, among others, in the treatment of tuberculosis. Its diethyl ether fraction has activity against H37Rv and multi-drugresistant strains (MIC 62.5 and $125.5 \mu \mathrm{g} / \mathrm{ml}$, respectively). Another flowering plant is Satyrium napalense, specifically, the $\mathrm{n}$-hexane fraction of its flowers. The MIC values are 15.7 and $62.5 \mu \mathrm{g} / \mathrm{ml}$ against sensitive and resistant strains [15]. The tree, native to Indomalaysia and Australasia, Melia azedarach, belonging to family Meliaceae, contains limonoids in its fruits, characteristic substances for Rutaceae of that family. There are active compounds, for example, 3-a-tigloyl-melianol with MIC $29 \mu \mathrm{M}$, but limonoid has no activity below $136 \mu \mathrm{M}$. 3-a-tigloyl-melianol has no toxicity on Vero cells which is very important for further research [16]. 
South America is another huge area where folk medicine is the main treatment. Allophylus edulis is an endemic plant of the region which is commonly known as a good anti-inflammatory remedy. Researchers have prepared an extract from the leaves of the tree from Brazil. The MIC of its essential oils is $157.5 \mu \mathrm{g} / \mathrm{ml}$, and varidiflorol's, which is the main component of the plant, is $190.0 \mu \mathrm{g} / \mathrm{ml}$. This result may indicate synergism between the components of A. edulis' extract, or that another component displays the most antimycobacterial active, and not the varidiflorol [17]. Plumbagin, a substance isolated from the root of Plumbago indica also has promising properties and is active against reference, MDR and XDR M. tuberculosis. Its MIC is between $0.25-31 \mu \mathrm{g} / \mathrm{ml}$, which is very low for the plant. Diospyrin from the stem bark of Diospyros montana and emodin from the stem bark of Ventilago madraspatana were tested by the same team of researchers and displayed good antitubercular activity, even against MDR and XDR strains [18]. Another plant which was multifaceted tested is Psidium guineense. This shrub or small tree grows in the central areas of South America. In traditional medicine it is used as an anti-inflammatory remedy and as a diuretic, or in the treatment of gastrointestinal disorders. Research proved that the essential oils of the leaves have moderate anti-tubercular activity and showed MIC values of $126.4 \mu \mathrm{g} / \mathrm{ml}$ [19]. A popular medicinal plant in Brazil, Doliocarpus dentatus, is used in folk medicine and the extract from the leaves displayed activity against $M$. tuberculosis with MIC values of $62.5 \mu \mathrm{g} / \mathrm{ml}$. Other tests demonstrated that the extract shows no toxicity and is safe to use as an anti-tubercular drug [20]. The azorellane and mulinane diterpenoids are interesting secondary metabolites of the Azorella compacta and Mulinum crassifolium plants from South America. It is unique that these substances have as much as 16 times higher antitubercular activity against resistance strains than streptomycin and rifampicin [21].

Canadian researchers tested plants from southern sites in New Brunswick, where extracts of branches and needles of Juniperus communis, rhizome of Aralia nudicaulis and the whole plant of Monesses uniflora, inhibited growth of Mycobacterium by about $90 \%$, which is almost the same as for rifampicin [22].

The countries of Africa are classified as developing countries, where most of society are poor and have no access to modern medical care. Traditional practitioners treat diseases with plants, animals and minerals. Voacanga genus are well-known trees in West Africa's folk medicine. Scientists tested the most popular species and proved that the most anti-mycobacterial component originated from Voacanga globose. Its MIC is $4 \mu \mathrm{g} / \mathrm{ml}$, which explains the usage of the plant in treatment. In comparison, in the same plant, researchers found that lupeol had no activity against M.tuberculosis [23]. Terminalia sericea, known among native African tribes, has quite potent anti-mycobacterial properties. The acetone stem bark extract has an MIC value of $0.025 \mu \mathrm{g} / \mathrm{ml}$ against reference and clinical strains [24].

Ocimum basilicum is a commonly known plant used in the kitchen worldwide as a spice. The plant is native to Asia, Africa and South America where it is used in folk medicine, for example, in the treatment of tuberculosis. Tests by researches have confirmed that basilica oil has antibacterial and antifungal properties. It is also known to have anti-mycobacterial activity (MIC higher than $6.25 \mu \mathrm{g} / \mathrm{ml}$ ) [25]. Similarly, Allium sativum is known in every kitchen as garlic. In traditional medicine
A. sativum is used as an effective antiviral and antibacterial natural drug. Tests of its extracts and isolates on mouse macrophage cells show that the crude essence of garlic is more potent than isolated substances. This may indicate synergism between compounds of garlic extract [26]. On the other hand, it has been proved that diallyl polysulfides play the main role in antibacterial activity. Mixes of these isolated compounds were tested and showed MIC values from 2.5-1.000 $\mu \mathrm{g} / \mathrm{ml}$. Additionally, isolations of A.sativum have hepatoprotective properties on a much higher level than sylimarine (even higher than $70 \%$ vs. $30 \%$ of protection, respectively). Unfortunately, the selectivity index is quite low and polysulfides were classified as a multifaceted cytotoxins [27].

Some researchers do not focus on the whole plant, nor do they extract and test mixes of components; instead, they prefer to explore the properties of pure plant-derivatives. Chinese scientists tested 100 substances of plant origin and recognized that only 12 compounds have some anti-tubercular properties, such as quercetin, kaempferol or curcumin. These substances are components of plants which are considered to have antibacterial properties, as demonstrated by experiments. The most active was hispidulin, a constituent of plants from the genus Artemisia or Salvia [28].

The activity of some extracts depends on solvents. The Turkish plants, Thymus sibthorpii, Satureja aintabensis and Micromeria Juliana, are the most effective in the fraction of ethyl acetate, even as much as 32-fold more potent (Micromeria Juliana) than in other solvents. Methanol and petroleum ether fractions have less anti-mycobacterial activity. All of those plants are active against $M$. tuberculosis, opposite to Stachys tmolea, Stachys thirkei and Ballota acetabulosa, which have no activity [29]. From among plants researched from Pakistan, the most active proved to be chloroform extracts of the leaves of Citrullus colocynthis and n-hexane extract of seeds Ricinus communis (MIC: $2.5 \mu \mathrm{g} / \mathrm{ml}$ ). Extraction of C.colocynthis with hexane produced 8-fold worse activity [30]. These differences were caused by the various structures of the active compounds, their polarity, solubility, etc. In fact, various fractions differed from one another's content of active substance. The solvent did not produce any activity. This could be because the isolated substances do not have enough anti-tubercular activity to be good candidates as drugs against Mycobacterium tubrculosis. This is very important information for other researchers investigating plants to discover new anti-mycobacterial drugs. An example of that contingency are substances isolated from Pisonia umbellifera, a plant from Taiwan, used in traditional medicine. Three isolates (pisodienone, a-hydroxypropiovanillone, (+)-ent-ficusol) display MIC $40 \mu \mathrm{g} / \mathrm{ml}$, which is the best antimycobacterial activity for this plant. In fact, it is of no interest to use MIC in treatment [31]. It is also possible that the experimental samples had no activity against Mycobacterium tuberculosis; an example of this are assays on extracts of green marine algae Cladophora rupestris, Codium fragile ssp. tomentosoides, Ulva intestinalis and Ulva lactuca. Researchers in the UK did not identify any anti-tubercular properties [32].

Despite the fact that science is in its golden age, new compounds are still being discovered. In fractions of the root wood of Zanthoxylum wutaiense, an evergreen shrub endemic to Taiwan, researchers found and 6 known substances 5 new ones. The compounds displayed activity against strain $\mathrm{H} 37 \mathrm{Rv}$ and had MIC values from 45.8 - 
$55.6 \mu \mathrm{g} / \mathrm{ml}$. However, this does not mean that they are as interesting as an anti-tubercular drug, but the synergistic effects of its anti-mycobacterial constituents are hopeful [33].

Synthesized derivatives of natural substances. There are many experiments which lead to the synthesis of new anti-turberculous substances. Synthesis based on natural substances with well-known construction give the best results, for example, ampicilin, an antibiotic, is a semi-synthetic derivate of penicillin [34]. Synthesized compounds with good anti-tubercular properties are derivatives of resorcinols from Ardisia gigantifolia. Pure, natural substances have an MIC from $34.4-79.2 \mu \mathrm{g} / \mathrm{ml}$, and the derivatives' MIC is even $22.2 \mu \mathrm{g} / \mathrm{ml}$ [35]. Methanol and acetate fractions of Curtisia dentata have MIC values classified as good activity - 22.2 and $44.2 \mu \mathrm{g} / \mathrm{ml}$. Isolated compounds of these extracts show no activity, but their derivatives - betulinic acid acetate and ursolic acid acetate - were much more active against M.tuberculosis (MIC: 19.8 and $3.4 \mu \mathrm{g} / \mathrm{ml}$, respectively) [36].

Micromolide from the stem bark of Micromelum hirsutum has good antitubercular activity in vitro $(\mathrm{MIC}=1.5 \mu \mathrm{g} / \mathrm{ml})$. For this reason, researchers strived to synthesize even more effective substances, but the trials were ineffectual - all synthesis increase anti-mycobacterial activity [37]. An almost identical situation occurred with derivatives of laubethanol [38] and formononetin [39]. Laubethanol isolated from Leucophyllum frutescens has an interesting MIC $25.1 \mu \mathrm{g} / \mathrm{ml}$ against M.tuberculosis H37Rv. However, only one of its many derivatives displayed more potent activity (dinitrobenzyl derivative), while none of other synthesized substances proved to be of interest [38]. This was similar to formononetin - only one derivative improved activity from $88 \%-95 \%$ inhibition [39].

It is surprising that not only new derivatives can have other antimycobacterial activities. Cinnamic acid is an example of a substance with 2 varied inhibition potencies. Transforming from cis-cinnamic acid to trans-cinnamic acid significantly increased the activity (120-fold), which is comparable to isoniazid and rifampicin [40], and seems to be a similar situation with the isolation of Alpinia galanga - 1' -acetoxychavicol acetate. This pure compound from a popular Thai herb shows MIC values 0.2 and $0.7 \mu \mathrm{g} / \mathrm{ml}$ against sensitive and resistant reference strains, respectively. The racemic 1' -acetoxychavicol acetate displayed worse activity which could mean that the second enantiomer has an antagonistic effect [41].

Endophytes. Many microorganisms, including fungi and bacteria, can be endophytes, which means they live in symbiosis with plants - they are a part of their host: leaves, stalks, etc. Endophytes do not cause any diseases. It is possible they can increase the production of specific substances or the nutritional values, increase biofuel and bioenergy from the plants, and reduce the effects of environmental stress [42]. Many endophytes, such as Amanita muscaria, Xerocomus badius, Suilus luteus, Trichoderma sp. and Streptomyces sp, have been examined for possible antituberculosis properties. They have an interesting MIC $(0.0625-200 \mu \mathrm{g} / \mathrm{ml})$ and a very high percent of inhibition (even as high as $96 \%$ ) $[43,44]$. These plants have been used mostly in traditional medicine to treat tuberculosis. It is surprised that, in fact, the active compound does not come from plant, but from the symbiotic organism. Glycyrrhiza glabra is commonly known as a medicinal plant, but its anti-tuberculous activity originates from Fusarium solani (MIC of compounds: $<1-256 \mu \mathrm{g} / \mathrm{ml}$ ) [45]. This occurred only in in vitro experiments, but if more advanced assays prove to be positive, it is possible that endophytes could be used as anti-tubercular drugs in the future.

Parasites. It is known that some parasites of plants can have anti-mycobacterial activity, one example of which is Fusarium $s p$. This fungus was isolated from the bark of Kordelia cande which grows naturally in China. The main component of this isolate is fusaric acid. Scientists synthesized chelates with cooper (II), cadmium (II), lead (II)), iron (II) and (III), manganese (II) and zinc (II). The Cu (II) complex displayed the best anti-tubercular activity (MIC $10 \mu \mathrm{g} / \mathrm{ml}$ ), and the activity of cadmium chelate was comparable with fusaric acid. Only those substances also had anti-mycobacterial activity against MDR clinical isolates. Other tested complexes had no activity (MIC > $60 \mu \mathrm{g} / \mathrm{ml}$ ) [46].

Synergism between natural substances with synthetic antituberculous drugs. The situation in which some natural substance decreases the MIC of a chemical anti-mycobacterial drug is very necessary. It allows physicians to use low dosages of drugs and the treatment is cheaper and less invasive. Isolation from Cynanchum atratum is an example of this. The main anti-tubercular substance is (-)-deoxypergularinine, the MIC of which is about $12,5 \mu \mathrm{g} / \mathrm{ml}$ against reference, and also the resistance of strains $M$. tuberculosis. Experiments show synergistic effects with rifampicin and isoniazid. Combination (-)-deoxypergularinine with these first-line anti-tubercular drugs increase MIC from 6- to 8-fold [47]. Interesting data was obtained by researchers from Indonesia. They tested extracts of 3 plants - Hibiscus sabdariffa, Kaempferia galangal and Piper crocatum in various dilutions in conjunction with standard drugs - rifampicin, streptomycin, ethambutol and isoniazid. They observed a percent of growth inhibition in 2 strains: isoniazid-ethambutol and rifampicin-streptomycin resistant. The best results were obtained in connection with rifampicin in almost all cases. Surprisingly, mixes of streptomycin and extracts inhibited the whole growth of the isoniazid-ethambutol resistant strain, but the rifampicinstreptomycin resistant strain displayed a maximum of $70 \%$ inhibition. Connection with $H$. sabdarifa showed only a $1 \%$ inhibition [48].

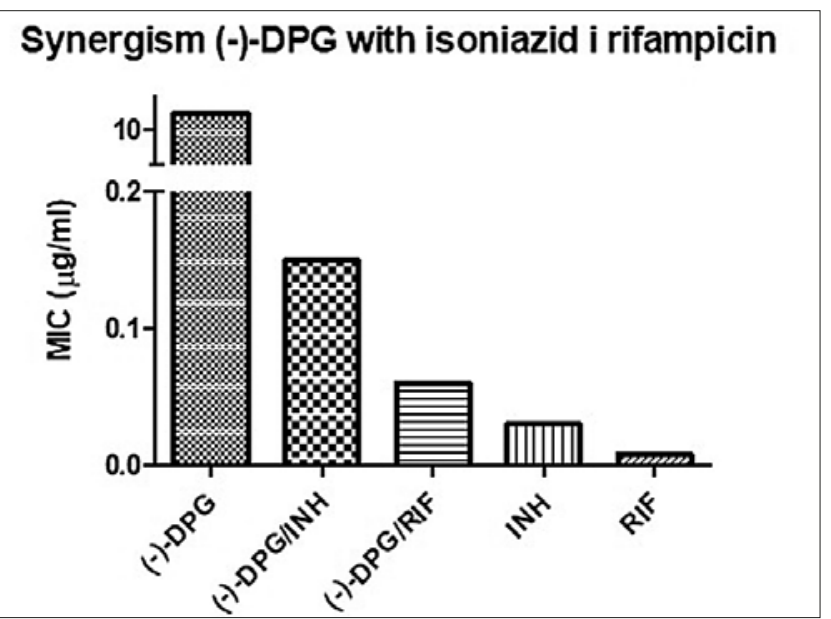

Figure 3. Synergistic effect (-)-DPG with isoniazid and rifampicin. (-)-DPG (-)-deoxypergularinine; (-)-DPG/INH -(-)-deoxypergularinine with isoniazid; (-)-DPG/ RIF - (-)-deoxypergularinine with rifampicin; INH - isoniazid; RIF - rifampicin [47]. 


\section{CONCLUSIONS}

The use of medicinal plants is still popular. People in developing countries who do not have access to medical care, consult healers about their diseases. Traditional practitioners treat them with drugs originating from natural sources. The main group of these medicines are plants, decoctions, powders or extracts, especially from the leaves, roots or flowers. They take these drugs without any evidence of their beneficial activity, but believe in their action. It is very important to investigate the natural medicines of the countries of the Third World to check their possible anti-tubercular properties. It will be useful for healer from these areas - if they know which of the plants they use have anti-mycobacterial activity - they could treat their patients more effectively.

These data are also important for the rest of the world, considering that there now exists a huge problem with the treatment of multi-drug-resistant tuberculosis, although some medicinal plants have such a property. Synthesis of derivatives of natural substances with proven properties is faster than the synthesis of de novo chemical drugs. Despite the enormous development of medicine and life sciences, much can still be learned from nature.

\section{REFERENCES}

1.G Virella. Mikrobiologia i choroby zakaźne. Wyd. 1. Urban\&Partner. 1999. p. 191-199.

2. WHO. Global tuberculosis report 2016.

3. K Kruczak, E Niżankowska-Mogilnicka. Gruźlica wielolekooporna - współczesne problemy. Pneumonol. Alergol, Pol. 2009. nr 77. p. 276 283.

4. CDC. Extensively Drug-Resistant Tuberculosis - United States. 1993 2006.

5. JRS Tabuti, CB Kukunda, PJ Waako Medicinal plants used by traditional medicine practitioners in the treatment of tuberculosis and related ailments in Uganda. Journal of Ethnopharmacology. 2010; 127: 130-136.

6. BG Elkington, K Sydara, A Newsome, C Hwa Hwang, DC Lankin, C Simmler, et al. New finding ofananti-TBcompoundinthegenus Marsypopetalum (Annonaceae) from a traditional herbal remedy of Laos. Journal of Ethnopharmacology. 2014; 151: 903-911.

7.SB Sanusi, M Fadzelly, A Bakar, M Mohamed, SF Sabran, MM Mainasara. Southeast Asian Medicinal Plants as a Potential Source of Antituberculosis Agent. Evidence-Based Complementary and Alternative Medicine. 2017.

8.R Gomez-Cansino, SL Guzman-Gutierrez, MG Campos-Lara, CI Espitia-Pinzon, R Reyes-Chilpa. Natural Compounds from Mexican Medicinal Plants as Potential Drug Leads for Anti-Tuberculosis Drugs. An Acad Bras Ciênc. 2017; 89(1): 31-43.

9.SB Lirio, APG Macabeo, EM Paragasb, M Knornc, P Kohls, SG Franzblau, et al. Antitubercular constituents from Premna odorata Blanco. Journal of Ethnopharmacology 2014; 154(2): 471-4.

10. MA Tan, H Takayama, N Aimi, M Kitajima, SG Franzblau, MG Nonato. Antitubercular triterpenes and phytosterols from Pandanus tectorius Soland. var. laevis. J Nat Med. 2008; 62: 232-235.

11. APG Macabeo, FA Tudla, K Krohn, SG Franzblau. Antitubercular activity of the semi-polar extractives of Uvaria rufa. Asian Pacific Journal of Tropical Medicine 2012; 5(10): 777-780.

12. YC Chien, CH Lin, MY. Chiang, HS Chang, CH Liao, IS Chen et al. Secondary metabolites from the root of Ehretia longiflora and their biological activities. Phytochemistry 2012; 80: 50-57.

13. H Seo, S Kim, H Al Mahmud, MI Islam, KW Nam, BE Lee, et al. In vitro Antitubercular Activity of 3-Deoxysappanchalcone Isolated From the Heartwood of Caesalpinia sappan Linn. Phytother Res. 2017; 31(10): 1600-1606.

14. WS Jang, MA Jyoti, S Kim, KW Nam, TK Quy Ha, WK Oh, et al. In vitro antituberculosis activity of diterpenoids from the Vietnamese medicinal plant Croton tonkinensis. J Nat Med. 2016; 70(1): 127-32.

15. M Bhatnagar, N Sarkar, N Gandharv, O Apang, S Singh, S Ghosal. Evaluation of antimycobacterial, leishmanicidal and antibacterial activity of three medicinal orchids of Arunachal Pradesh, India. BMC Complementary and Alternative Medicine. 2017; 17(1): 379.

16. Sanna G, Madeddu S, Giliberti G, Ntalli NG, Cottiglia F, De Logu A, et al. (2015) Limonoids from Melia azedarach Fruits as Inhibitors of Flaviviruses and Mycobacterium tubercolosis. PLoS ONE. 2015; 10(10): e0141272.

17. LFN Trevizana, K F do Nascimentoa, JA Santosb, CA L Kassuyab, CAL Cardosoc, MD C. Vieira et al. Anti-inflammatory, antioxidant and anti-Mycobacterium tuberculosis activity of viridiflorol: the major constituent of Allophylus edulis (A. St.-Hil, A Juss \& Cambess) Radlk. Journal of Ethnopharmacology, 2016; 192: 510-515.

18. D Dey, R Ray, B Hazra. Antitubercular and Antibacterial Activity of Quinonoid Natural Products Against Multi-Drug Resistant Clinical Isolates Phytother Res. 2014; 28(7): 1014-21.

19. KF do Nascimento, FMF Moreira, JA Santos, CAL Kassuya, JHR Croda, CAL Cardoso et al. Antioxidant, anti-inflammatory, antiproliferative and antimycobacterial activities of the essential oil of Psidium guineense Sw. and spathulenol, Journal of Ethnopharmacology. 2018; 10 210: 351-358.

20. RB Ishikawa, MM Leitão, RM Kassuya, LF Macorini, FMF Moreira, CAL Cardoso et al. Anti-inflammatory, antimycobacterial and genotoxic evaluation of Doliocarpus dentatus, Journal of Ethnopharmacology. 2017; 204: 18-25.

21. GM Molina-Salinas, J Bórquez, S Said-Fernández, LA Loyola, A YamPuc, P Becerril-Montes, et al. Antituberculosis activity of alkylated mulinane diterpenoids. Fitoterapia. 2010; 81(3): 219-222.

22. TE O'Neill, H Li, a CD Colquhoun, JA Johnson, D Webster, CA Gray. Optimisation of the Microplate Resazurin Assay for Screening and Bioassay-guided Fractionation of Phytochemical Extracts against Mycobacterium tuberculosis. Phytochemical Anal. 2014; 25(5): 461-467.

23. H Hussain, J Hussain, A Al-Harrasi, IR Green. Chemistry and biology of the genus Voacanga. Pharmaceutical Biology. 2012; 50(9): 1183-1193.

24. NI Mongalo, LJ McGaw, TV Segapelo, JF Finnie, J Van Staden, Ethnobotany, Phytochemistry, Toxicology and Pharmacological properties of Terminalia sericea Burch. ex DC. (Combretaceae)- A review, Journal of Ethnopharmacology. 2016; 194: 789-802.

25. BS Siddiqui, HA Bhatti, S Begum, S Perwaiz. Evaluation of the antimycobacterium activity of the constituents from Ocimum basilicum against Mycobacterium tuberculosis. J Ethnopharmacol. 2012; 144(1): 220-222.

26.SS Nair, SS. Gaikwad, SP Kulkarni, AP Mukne. Allium sativum Constituents Exhibit Anti-tubercular Activity In vitro and in RAW 264.7 Mouse Macrophage Cells Infected with Mycobacterium tuberculosis H37Rv. Pharmacogn Mag. 2017; 13(Suppl 2): S209-S215.

27. C Oosthuizen, M Arbach, D Meyer, C Hamilton, N Lall. Diallyl Polysulfides from Allium sativum as Immunomodulators, Hepatoprotectors, and Antimycobacterial Agents. J Med Food. 2017; 20(7): 685-690

28. Y Zheng, X Jiang, F Gao, J Song, J Sun, L Wang, et al. Identification of plant-derived natural products as potential inhibitors of the Mycobacterium tuberculosis proteasome. BMC Complement Altern Med. 2014; 14: 400.

29. T Askun, E M Tekwu, F Satil, S Modanlioglu, H Aydeniz. Preliminary antimycobacterial study on selected Turkish plants (Lamiaceae) against Mycobacterium tuberculosis and search for some phenolic constituents. BMC Complement Altern Med. 2013; 13: 365.

30.S Ullah, S Hussain, SN Khan, M Khurram, I Khan, MA Khan. The medicinal plants in the control of tuberculosis: Laboratory study on medicinal plants from the Northern Area of Pakistan. Int J Mycobacteriol 2017; 6(1): 102-5.

31.HT Kuo, CF Peng, HY Huang, CH Lin, IS Chen, IL Tsai. Chemical Constituents and Antitubercular Activity of Formosan Pisonia umbellifera. Planta Med. 2011; 77(7): 736-741.

32. J Spavieri, M Kaiser, R Casey, S Hingley-Wilson, A Lalvani, G Blunden et al. Antiprotozoal, Antimycobacterial and Cytotoxic Potential of Some British Green Algae. Phytother Res. 2010; 24(7): 1095-1098.

33. HY Huang, T Ishikawa, CF Peng, S Chen, IS Chen. Secondary Metabolites from the Root Wood of Zanthoxylum wutaiense and Their Antitubercular Activity. Chem Biodivers. 2011; 8(5): 880-6.

34. Ampicillin identification. DrugBank. https://www.drugbank.ca/drugs/ DB00415 (24.10.2017)

35. YF Guan, X Song, MH Qiu, SH Luo, BJ Wang, NV Hung, et al. Bioassay-Guided Isolation and Structural Modification of the Anti-TB Resorcinols from Ardisia gigantifolia.. Chem. Biol. Drug Des. 2016; 88(2): 293-301.

36. VO Fadipe, NI Mongal, AR Opoku, PM Dikhoba, TJ Makhafola. Isolation of anti-mycobacterial compounds from Curtisia dentata 
(Burm.f.) C.A.Sm (Curtisiaceae). BMC Complement. Altern. Med. 2017; 17: 306

37. H Yuan, R He, B Wan, Y Wang, GF Pauli, SG Franzblau, AP Kozikowski. Modification of the side chain of micromolide, an anti-tuberculosis natural product. Bioorg. Med. Chem. Lett. 2008; 18(19): 5311-5315.

38.J Perez-Meseguer, E del Olmo, B Alanis-Garza, R Escarcena, E GarzaGonzález, R Salazar-Aranda et al. Synthesis of Leubethanol derivatives and evaluation against Mycobacterium tuberculosis. Bioorg Med Chem. 2012; 20(13): 4155-4163.

39. P Mutai, E Pavadai, I Wiid, A Ngwane, B Baker, K Chibale, Synthesis, Antimycobacterial evaluation and pharmacophore modeling of analogues of the natural product formononetin. Bioorg Med Chem Lett. 2015; 25(12): 2510-3.

40. YL Chen, ST Huang, FM Sun, YL Chiang, CJ Chiang, CM Tsai, et al. Transformation of cinnamic acid from trans- to cis-form raises a notable bactericidal and synergistic activity against multiple-drug resistant Mycobacterium tuberculosis. Eur J Pharm Sci. 2011; 43(3): 188-194.

41.S Warit, K Rukseree, T Prammananan, P Hongmanee, P Billamas, $S$ Jaitrong, et al. In Vitro Activities of Enantiopure and Racemic 10 -Acetoxychavicol Acetate against Clinical Isolates of Mycobacterium tuberculosis. Sci Pharm. 2017; 85: 32.

42. C Mei, BS Flinn. The Use of Beneficial Microbial Endophytes for Plant Biomass and Stress Tolerance Improvement. Recent Pat on Biotechno. 2010; 4(1): 81-95.
43. A Alvin, KI Miller, BA Neilan. Exploring the Potential of Endophytes from 1 Medicinal Plants as Sources of Antimycobacterial Compounds. Microbiol Res. 2014; 169(7-8): 483-95.

44. AY Gordien, AI Gray, K Ingleby, SG Franzblau, V Seidel. Activity of Scottish Plant, Lichen and Fungal Endophyte Extracts against Mycobacterium aurum and Mycobacterium tuberculosis, Phytother Res. 2010; 24(5): 692-698.

45. A Shah, MA Rather, QP Hassan, MA Aga, S Mushtaq, AM Shah, et al. Discovery of anti-microbial and anti-tubercular molecules from Fusarium solani: an endophyte of Glycyrrhiza glabra. J Appl Microbiol. 2017; 122(5): 1168-1176.

46. JH Pan, Y Chen, YH Huang, YW Tao, JWang, Y Li etal. Antimycobacterial Activity of Fusaric Acid from a Mangrove Endophyte and its Metal Complexes. Arch Pharm Res. 2011; 34(7): 1177-1181.

47. KW Nam, WS Jang, MA Jyoti, S Kim, BE Lee, HY Song. In vitro activity of (-)-deoxypergularinine, on its own and in combination with anti-tubercular drugs, against resistant strains of Mycobacterium tuberculosis. Phytomedicine. 2016; 23(5): 578-82.

48. PN Fauziyah, EY Sukandar, DK Ayuningtyas. Combination Effect of Antituberculosis Drugs and Ethanolic Extract of Selected Medicinal Plants against Multi-Drug Resistant Mycobacterium tuberculosis Isolates. Sci Pharm. 2017; 85(1): 14. 